Article

\title{
A Year in the Life of a Public Park: Route-Making, Vigilance and Sampling Time Whilst Walking
}

\author{
Wayne Medford \\ Wolfson Research Institute for Health and Wellbeing, Durham University, Durham DH1, UK; \\ Wayne.medford@durham.ac.uk
}

Received: 22 October 2017; Accepted: 18 February 2018; Published: 21 February 2018

\begin{abstract}
This paper offers a systematic, experimental, walking methodology to facilitate an ethnography of a major urban public park undertaken in the north-east of England in 2009-2010. Ethnography puts the body in-place, placing the senses within the streams of life to be observed through experience; walking is one means of so doing. Walking traditions have frequently been used to observe, record and analyse the minutiae of urban life, with recent qualitative methodologies seeking to use walking to underpin ethnographies. Walking must negotiate the specificity of place and time, with all walks taking place in a real-world of materially, spatially, complex, vital and rhythmic landscapes. My aim was to systematically capture some of these patterns. Ethnographies typically use sustained field-based immersion; yet, some research utilises sampling strategies to guide observational procedures. Combining these methodologies allowed me to develop a methodology with three objectives: to create a series of routes to be followed; routes which allowed me to both scan and closely observe distant, and proximate, surroundings; and to construct a diurnal, weekly "sampling" frame, which allowed me to "immerse" myself within the park's life through repeatedly walking these routes, building up a picture of everyday life, whilst (hopefully) capturing unscheduled events.
\end{abstract}

Keywords: ethnography; phenomenology; walking; digital mapping; assemblage; sampling; dwelling; therapeutic landscapes; urban public parks

\section{Introduction: Saltwell Park}

With respect to the UK and USA, public parks were developed with human and societal health in mind. Taylor (1999) lists several benefits, but of relevance here are: (1) spaces that bring natural features into the city landscape; (2) spaces that bring people into contact with natural entities, and with members of local society, also different to themselves; (3) spaces that promote certain "approved" behaviours; and (4) spaces that produce healthy outcomes. Furthermore, politicians and designers determined that parks were to be open to all and socially democratic (e.g., Olmsted 1997; Olmsted 1973). Recent commentaries on public parks have highlighted their use within public policy initiatives for improving social cohesion (Peters et al. 2010; Forrest and Kearns 2000; Conway 2000), and popular attitudes towards wildlife and the great outdoors (Goltsman et al. 2009), as well as improving human health (Wheater et al. 2007).

Within the centre of the urban mass of Gateshead, lies Saltwell Park (Figure 1). It is 22 hectares in size, built on the slope of a wide valley. It was opened in 1876, on what was then the outskirts of the town, but is now between residential districts. To the north, Bensham and Saltwell; to the east, Low Fell. The official narratives around Saltwell Park are those of a much-valued space, especially since it was the subject of a large, early 2000's, restoration project. Gateshead Metropolitan Borough Council owns several greenspaces, but only Saltwell Park is afforded major publicity, especially given other 
urban parks exist within the town ${ }^{1}$. The council website offers several dedicated webpages informing the reader about the park: its history; visiting it, and what the visitor will find and can do there; the Friends Group; the Model Boat Club; the annual major winter son et lumière event, Enchanted Park (details for 2017); and awards which the park gathered (oddly enough only between 2005-2010). The website for "NewcastleGateshead Initiative", the destination management and marketing agency for the combined "NewcastleGateshead" area², also publicises Saltwell Park; here, it is one of several significant public parks across Tyneside, and one of few within Gateshead to be mentioned. The park has been the winner of several national, high-profile awards for parks and greenspace ${ }^{3}$. The UK-wide "The Green Flag Award scheme" is awarded for the management of recreational outdoor spaces across the United Kingdom and globally; Saltwell Park has tended towards serial Green Flag wins, again since restoration ${ }^{4}$. Other private webpages tend to proclaim the park as a family-friendly attraction, and as a space beloved by local residents.

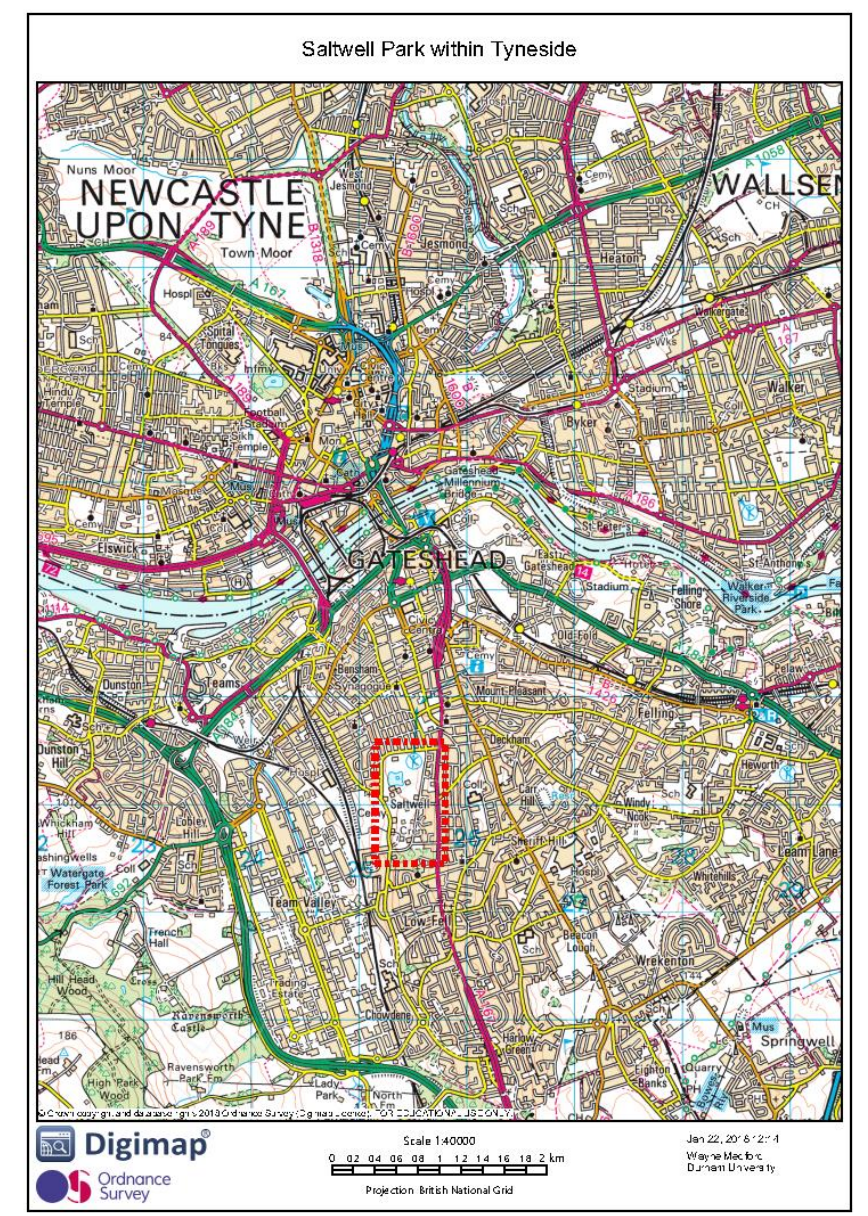

Figure 1. Saltwell Park, Gateshead.

Saltwell Park is also known as the "People's Park" (Gateshead MBC 2010). Saltwell and Bensham are cited as having particularly socially and ethnically diverse populations. There is a large and prominent Hasidic Jewish population within the borough, the third largest in Britain (Gateshead MBC 2005);

\footnotetext{
http:/ / www.gateshead.gov.uk/Leisure\%20and\%20Culture/parks/home.aspx (accessed on 8 January 2018).

2 http://www.ngi.org.uk/about-us/ (accessed on 8 January 2018).

8 January 2018).

4 http://www.greenflagaward.org.uk/ (accessed on 8 January 2018).
} 
this population is concentrated immediately to the north of the Park. The park is the focus of civic pride (see Figure 2 below).

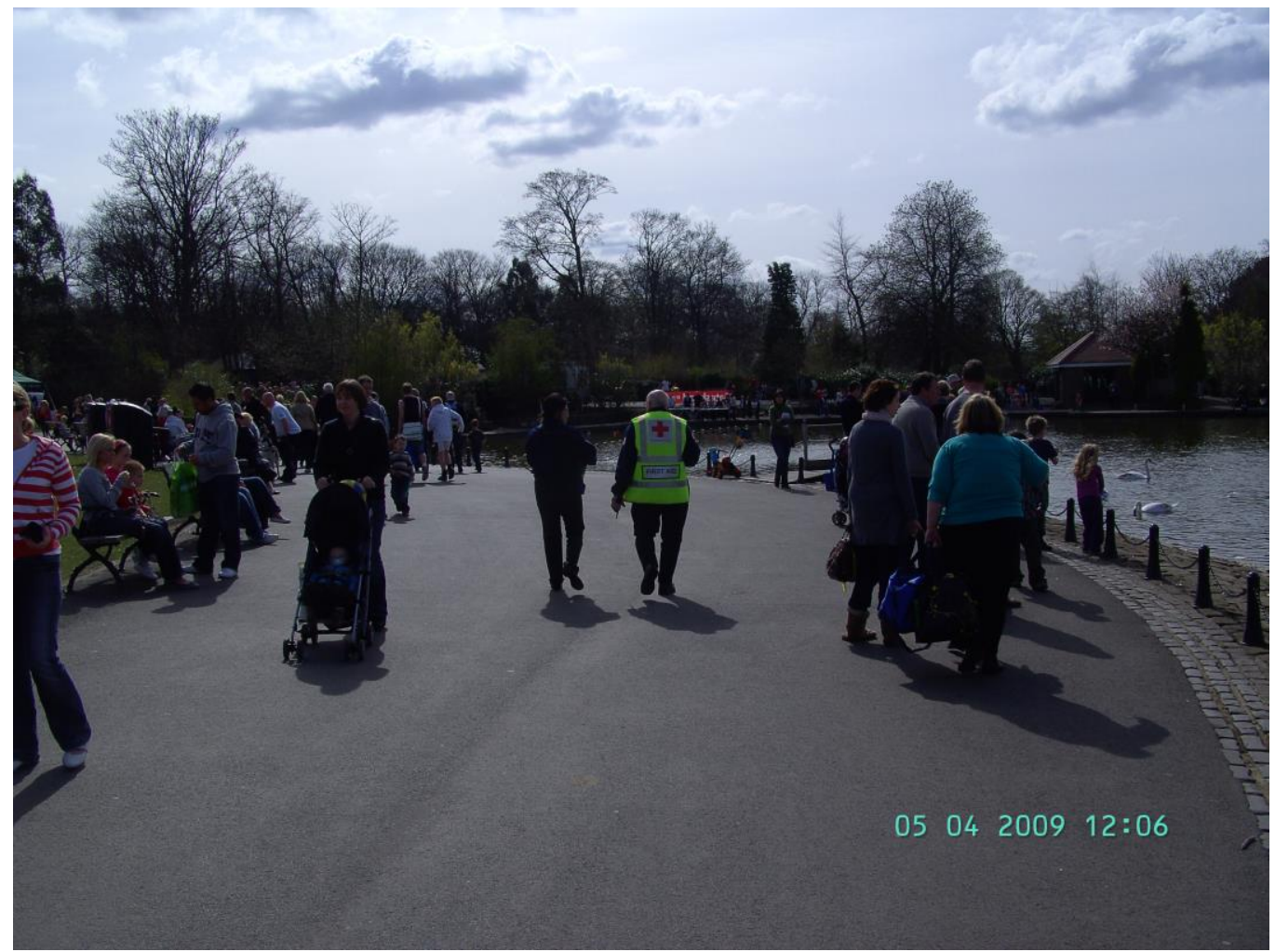

Figure 2. The Sunday of the Spring Saltwell Park Show weekend, 2009.

Several social groups dwell there. There are semi-official groups, such as the Friends' and the model boaters. The park has a staff contingent, with catering, grounds' maintenance, visitor education and liaison, and wardening roles. Early on, I learned that some 100,000 visits are made to the Park annually. Apart from Christmas Day, visitors can enter on any day, or may be attracted by scheduled day events, which tend to be held during spring, summer, and autumn.

What kind of space would the visitor encounter, staff member work within? The terrain slopes down from east to west. The landscape is relatively open visually, offering a mixture of long, broad, vistas and some more hidden views (see Figure 3 below). The southern third and northern half of the park are relatively open, with the middle portion more enclosed. These spaces are interconnected by an extensive footpath network (as can also be seen on Figures 4 and 5 later).

My paper is concerned with how to explore Saltwell Park, through devising and using a methodology which will allow for pedestrian-based ethnography and documentation of the everyday life of an area of the urban, over the course of a year. Specifically, my research was situated within the literature of therapeutic landscape. What I discuss here was part of a larger project ${ }^{5}$ to map and analyse those Saltwell Park factors of landscape and life which could be considered "therapeutic" for health (e.g., Gesler 2003; Gesler 2005; Williams 2007). As well as human and nonhuman connectedness and sociability, other themes of the therapeutic landscape literature suggest that a sense of place, and place-related psychosocial attachments, are important (e.g., Cattell et al. 2008; Gesler 2003). Some of results obtained are suggestive of these dimensions.

5 http://etheses.dur.ac.uk/5571/ (accessed on 8 January 2018). 


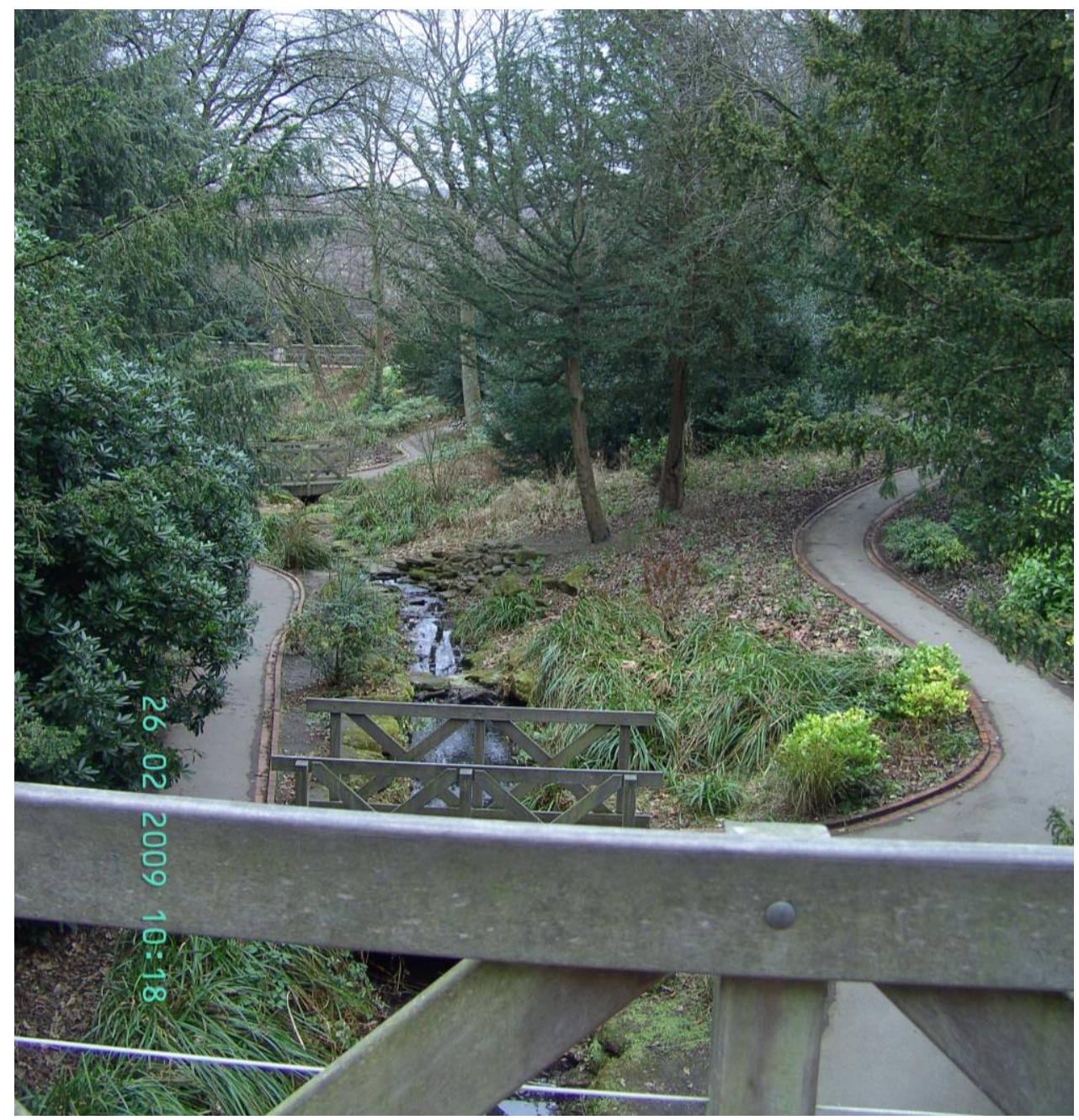

Figure 3. The Dene.

Of interest to me was an attempt to identify within Saltwell Park "the complex habitations, practices of dwelling, embodied relations, material presences, placings and hybrid subjectivities" (Merriman 2004) which appear to have the potential to affect human health. In line with post-structural theorisations of place, and my pilot work, I considered the park as being a space of change and flux. The park offered not just a steady, "unchanging" landscape, see (Ingold 2010b), but variations which operated across spatialities and temporalities, outside official, or accepted, designs and designations.

The empirical data for the wider project arose from my pedestrian mapping (discussed here), as well as participatory observations, and interviews with selected staff and visitors who use and dwell within. This was to weave the observable layout of spaces to embodied experiences and lifecourses within the park's life. Within this paper, I discuss how both the complex materialities, spatialities and temporalities of Saltwell Park, with their seasonal patterns, determined that I observed the multiple human and nonhuman entities which comprise the place of Saltwell Park, as well as those interactions, commentaries and experiences which influence human health. Some of the selected results which I discuss later reflect some of the original aims of public parks, such as social inclusivity, and interactions with Nature.

The body-in-place can facilitate the exploration of everyday life; walking traditions have often been used to explore urban life. However, discussions of such work have tended towards singular explorations of a given locality within an urban area, despite urban life having rhythms and flows. 
I modelled Saltwell Park as a space of large physical extent, continually being reordered through time across its entirety, so that it was not a space of stasis; this suggested that I follow a walking methodology to entangle myself within these complexities and flows. Furthermore, one pedestrian exploration may not have captured the intricacies of the possible positive place effects and interactions. I explain how a systematised repeating of walking explorations, with an attendant close attentiveness to my surroundings, was intended to explore the everyday and the regular, as well as the exceptional and the ephemeral. I used sampling techniques from observational methods outside of walking traditions to inform my methods.

In the results section, I discuss only some of the facets of Saltwell Park's diurnal and annual lives, which suggested possible therapeutic experiences. I also illustrate some of the ways in which individuals could find therapeutic dwellings through their own inhabitation. Furthermore, I became another participant, through my own fieldwork dwellings as fieldwork pedestrian, and through coincidentally joining the Friends' group, at the same time. I was thus situated within two realms within the park, which sometimes coincided.

I end by suggesting that these methods can be utilised elsewhere within urban landscapes. My semi-structured approach is not offered as an alternative to more improvised explorations of space, but as a (hopefully) useful complementary methodology to dwell within a given location.

\section{Place and Walking}

Walking is the best way to explore and exploit the city; the changes, the shifts [...]. (Sinclair 1997)

This Sinclair quotation points to various elements of a walk: the location and wider urban landscape in which it is performed; actions during the walk; and the person undertaking it (their subjectivity, as well as their walking intentions), to self and landscape, at that moment (the "in action-in-space", (Sotelo 2010).

Explorations of place and landscape are becoming reconnected with phenomenology, and a placing of the body and self within spatial constitution (Cheng 2014). This foregrounds an attentiveness to everyday place formations. Such attentiveness draws attention to "the "dailyness" of urban life: those routines, habits, behaviours and objects that seem to allow much of city life to cohere" (Latham and McCormack 2007). Ethnographic research is thus facilitated by the body-in-place as a research methodology (Kusenbach 2003; Pink 2008).

Walking has long been associated with the acquisition, and production of, ethnographic and geographical insights (Pink et al. 2010). Ingold (2016a) argues in his essay Culture on the Ground that "locomotion, not cognition, must be the starting point for the study of perceptual activity". Lefebvre, Jacobs (2016) and Anderson (2000) have drawn attention to the minutiae of city life: how banal, everyday, occurrences are furnished and shaped through material complexity (Hillier 1996), fluidity (Whyte 1988), vitality, and temporal rhythms (Castells 1972; Lynch 1984; Lefebvre 2004). As Billo and Mountz (2016), and Bendiner-Viani (2016) demonstrate, ethnographies can be undertaken and produced for the spatial and as well as the cultural, reflecting an appropriate methodology for attending to how space and groups interact, and co-produce each other.

Sinclair's declaration raises three issues which need to be attended to, within the creation a regular, repeatable methodology, within a vital landscape. The first theme which I raise from Sinclair's declaration is planning walks. Place has been seen as more open, relational and inclusive (Massey 1991; Massey 2005). Humans do not live outside a landscape (Ingold 2000), nor move across one (Merriman 2004); instead, humans are caught within the "flows and associated frictions and turbulences integral to the construction and performance of landscapes and places" (Merriman 2004). Places and landscapes are continually "ordered, practised and placed through the folding together of different materials, atmospheres, spaces and times" (Merriman 2004). Similarly, Massey (1994) notes that "localities are not just about physical buildings, ... they are about the intersection of social activities and social relations and crucially, activities and relations which are necessarily, by definition, dynamic, changing". Conradson (2005) discusses how the formation of therapeutic 
spaces arises through the "assemblage" of multiple entities, within which humans interact with other humans, as well as the nonhuman; such ecologies are dynamic, arising through "jostling and engage[ment]". An important dimension of this is affect, the capacity to influence action and emotion. The hybrid subjectivities, senses-of-place, dwelling, home and sociality, which not only emerge through engagement, but which also play a part in psychosocial health, emerging through Merriman's pleats and folds, have diverse spatialities and temporalities, ranging from the momentary to the longer-term.

Traditional descriptions of the urban foreground its dynamism, especially observable whilst on-foot (see Benjamin and Lefebvre). If such dynamism is of interest, or will influence the patterns of life observed, then it must be incorporated into planning one's walking. To walk is to walk through a landscape, to walk around, or through, place (Lee and Ingold 2006). Matos Wunderlich (2008) highlights the differing spatialities and temporalities of walking performance, commenting that

[W]alking is an unconscious way of moving through urban space, enabling us to sense our bodies and the features of the environment. With one foot-after-the other, we flow continuously and rhythmically while traversing urban place. [ ] While "walking" in the city, we perform in space-time, becoming immersed in temporal continuums of social everyday life activities fused with spatial and natural rhythmical events. (Matos Wunderlich 2008)

Thus, of further relevance, is the route on the ground that the walker will follow, which will allow for that sensing. Walking traditions have varied between the whimsical drift of the dérive, and more deliberate route-making being planned beforehand. To perform a walk requires (even some slight and acquired) knowledge of the urban landscape in question, and the planning of a walk that will allow the apprehension of some of these particular dynamic dimensions.

Second is how intention and attention are directed while walking. Edensor (2010) observes that "[t]he rhythms of walking allow for a particular experiential flow of successive moments of detachment and attachment, physical immersion and mental wandering, memory, recognition and strangeness." Walking methodologies split roughly into a triptych of those who walk to discover, closely observe and record their surroundings; those who saw the landscape as a canvas upon which to perform a particular aesthetic or political act; or as a space of contemplation of environment and self (Bassett 2004). My focus here is on the first; how might one pay attention to, and record, one's surroundings. Like Cheng (2014), my attention would be drawn to objects- (and people-) in-place. Of particular relevance here are those persons, behaviours, processes, objects, etc., which were suggestive of inclusivity and accessibility; physical activity; sociability; and a sense of place and meaning.

Drifting purposefully is the recommended mode ... but the born again flâneur is a stubborn creature, less interested in texture and fabric, eavesdropping on philosophical conversation pieces, than in noticing everything. (Sinclair 1997)

I too was interested in noticing everything. Sontag (1978) refers to "[the] solitary walker reconnoitering, stalking, cruising the urban inferno". Observational methods such as ethnography and participant observation allow a researcher to develop a deeper and more nuanced understanding of people's everyday lived experiences (e.g., Cook 2005), and within urban neighbourhoods (Cattell et al. 2008). Smith and Hall (2016) discussed the work of a homeless "outreach" team which undertook daily patrols to repeatedly search for, approach and engage with clients on the streets of Cardiff city centre. The team's mobilities are informed by the necessary alertness (similar to Sinclair's sensibility above) required to locate and engage with elusive, ever mobile, clients.

Acutely purposive ... it a participatory exploratory activity-ranging across the city, attentive to what the urban landscape might hold, or offer up ... a tentative sensitivity to the possibilities introduced by moving carefully ... alert to what just might be the sort of thing you are looking for. (Smith and Hall 2016)

Smith and Hall (2016) describe their activities as "streetcombing", a "“roving attention" that "animates" the urban landscape", a similar engagement perhaps to hunting practices. 
Heddon and Turner (2010) relate that when walking, artist Linda Cracknell extends her vigilance to her immediate micro-landscape, following in the footsteps of de Certeau and Benjamin, recording surroundings, as well as impressions and reflections, to create a narrative. In a similar vein, Macfarlane continues, asking us to

Record the experience as you go ... Be alert to the happenstance of metaphors, watch for visual rhythms, coincidences, analogies, family resemblances, the changing moods of the street. (MacFarlane 2005)

Here, MacFarlane proffers a method for interacting with one's surroundings, based upon constant alertness. McCabe (n.d.) comments that this approach is attentive for the poetry of the unexpected, the coincidental, the common thread of deciphered and imbued meanings, and calls for suitable attentiveness to the overheard conversation, found objects, or historical connections. As with the examples above, I was constantly on alert, scanning my surroundings with all my senses.

The final question is temporal, related to the possible flux of one's surroundings and one's aims and objectives for the walk: how much time does the walker spend within the location? Discussions of city life of course highlight movement, flow and rhythms, which occupy and structure time-space; these tend to focus on immediate hustle and bustle. However, longer temporal rhythms exist in city life, such as those of the seasons. Any public park, just as any street, is open to the weather-world (Ingold 2010a), of immediate weather (Bennett 2005), and longer seasonal trends. The social life of the city may incorporate events which are occasional, or rhythmic too.

Traditionally, one facet of ethnographic methodology is long durations in the field, to fully apprehend and understand the minutiae of everyday life. That life may have rhythms and patterns of activity which occur for, or at, select times, whether diurnally or seasonally. Walking traditions have often tended to configure "project" aims and objectives around a single walk. The empirical data gathered may be sufficient for one's purposes from a single excursion. Yet if spatial form and co-produced life is revealed as vital and fluid, what length of time, or which location, will best reveal a relevant aspect of this? Will walking during one time of the day reveal similar aspects compared to walking during another, such as night-time (Morris 2011)? Can walking reveal seasonal variations in one's surroundings? My theme here is centred on immersion, in the vein of traditional ethnography (Jeffrey and Troman 2004). However, writers have drawn attention to the difficulties of continuous access to (Smets et al. 2014), and being able to immerse one's self for a single time-space, requiring the need to employ non-synchronous observations, being mobile to follow phenomena (Freidberg 2001b; Dalsgaard and Nielsen 2013), or limit times spent in the field (Harrington 2015). Madden (2017) observes that "step-in-step-out" ethnography allows for different (longer or shorter) phases of field engagement, but he still emphasises that long-term or "step-in-step-out" engagements have the same aims and objectives. I discuss how time spent in the field can be arranged using a sampling pattern to sample the city life and landscape under consideration.

Ethnographies of city space tend to focus upon life in purely hard landscapes, of the street and square. Urban parks are part of, yet not necessarily of, the city (Boyd 2009). I am concerned with here describing and discussing the methodologies which I used to undertake pedestrian surveys of the park, over the course of one year. The aim was to create strategies which were not fixed and inflexible, but were in fact "semi-structured". As with Ochoa (2009), I wished to systematise my walks, to create a "more complete apprehension of urban space ... to go through, to see and simultaneously interrogate what is seen to register what is seen; to relate, to interpret and to evaluate what is seen". My approach was therefore to develop a method that would allow me to interpret Saltwell Park as a lively therapeutic space, but using time efficiently, looking for both the everyday and the exceptional.

\section{My Walking Methodologies}

Before planning fieldwork proper, I undertook initial pilot survey work within the park. I built up a picture of these various components of the "assemblage" of the park, including both the physical and 
social "actors" in the assemblage. I was conscious of a space that was materially complex, inhabited, open to weather and seasonal entities.

Saltwell Park is physically bounded, is large, so much so that the body (and senses) must journey around and through it, to apprehend that extent. Each part of the park can be thought of as comprising areas with varying character, each of which are constituted of different entities, such as vegetation, water, shrubs and flowers, wildlife, constructed features, and individuals' behaviours. Those vistas which are needed to gauge that physical extent can be obscured by the mixture of pre-existing topology and the deliberately located vegetation, suggesting journeys towards, through, around, under, and over spaces. Vegetation is vital and lively, as are other forms of nonhuman park life (e.g., Thomson 2007). Saltwell Park, in common with other public parks, has an existing footpath network, which criss-crosses the park, which especially suggested movement towards, away from, and alongside others.

During several days' preliminary pilot surveys (two weeks observations and inquiry of on-site staff, split between summer and autumn 2008), I noted variations in the hours of public admittance through the year. The park has 10 gated entrances which are locked upon closing. Normally, the park is open from roughly dawn to dusk; in July, this time-window is about $13 \mathrm{~h}$, whereas in December it is only about $7 \mathrm{~h}$.

My walking methodology was to incorporate an investigation of as many different spaces within the park, and to gather empirical data on the life within. This suggested a systematic route-making and route-following. I wanted to investigate the boundaries of the space, as well as its interior. My approach was to incorporate something from these various traditions. Similar to MacFarlane (2005), I used a map of the park to initially guide my route-making. I determined that my plan to create routes through the park had to have some structure, and could not be entirely be guided by the chance characteristics of proximate ambience. Thus, the routes would operate as a form of constant against the everyday fluidities. My initial instinct was to try to incorporate the footpath network.

In the pilot phase, I devised two different routes through the park that allowed me to observe as many different sub-areas of the park as possible during each visit. Table 1 illustrates my two main routes around the park (also refer to the map on Figures 4 and 5). I chose a selection of routes, along this same network, which took me through the interior subspaces, as well as close to the exterior subspaces.

Table 1. Two semi-structured Data-Gathering Walking Routes through the park.

\begin{tabular}{cc}
\hline Route $\mathbf{1}$ & Route $\mathbf{2}$ \\
\hline Car park/Crematorium & Car park/Crematorium \\
Bandstand/The Grove & Bandstand/The Grove \\
South African War Memorial & South African War Memorial \\
& Octagonal garden \\
& Aviaries \\
Maze & Stableblock \\
Towers & Almond Pavilion \\
Dene & Sports Pitches \\
Rose Garden & The Lake and Sports Courts \\
Bowling greens & Rose Garden \\
Almond Pavilion & Dene \\
The Towers, and return & Past South African War Memorial, and return
\end{tabular}




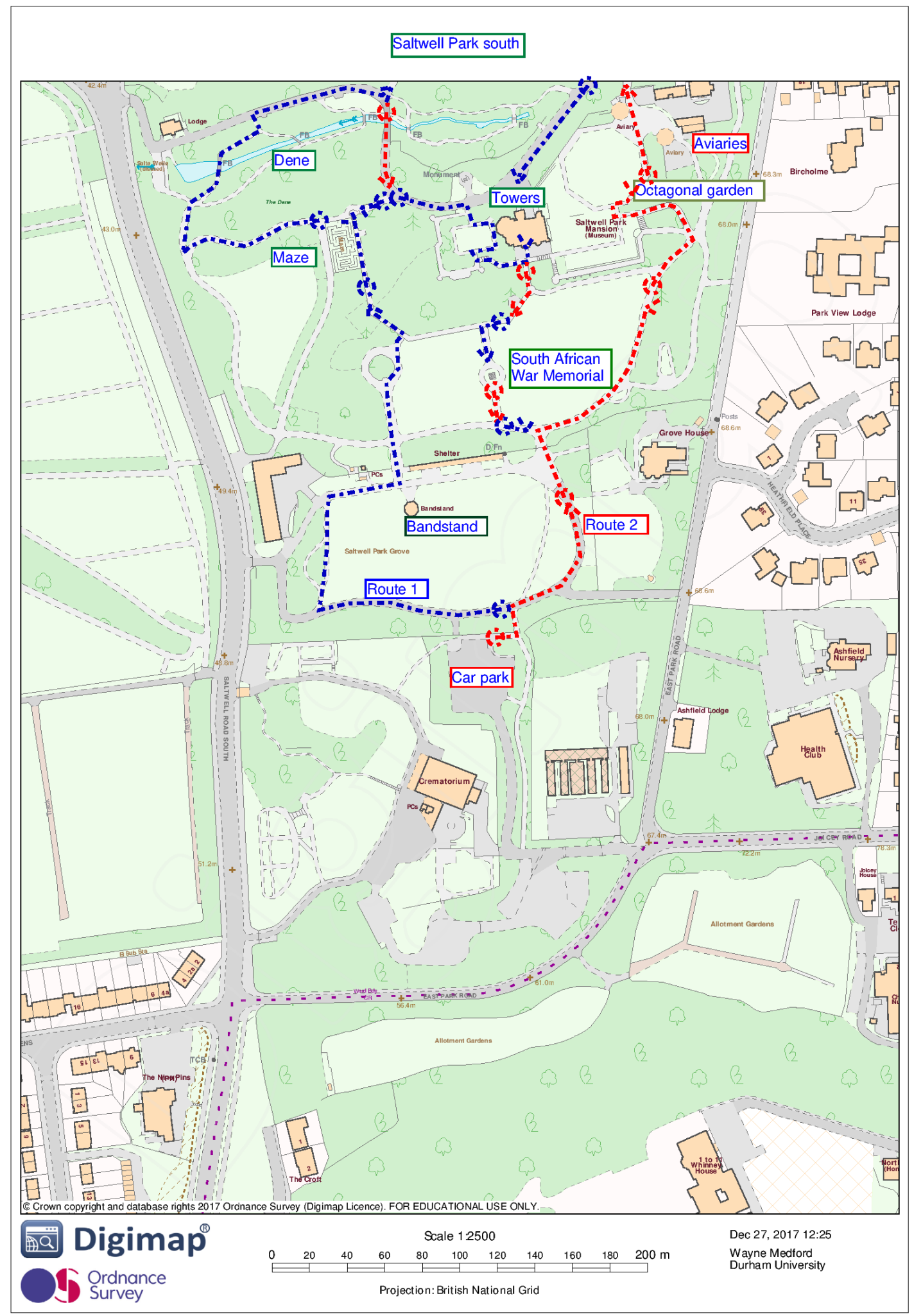

Figure 4. Walking routes through the southern half of Saltwell Park. 


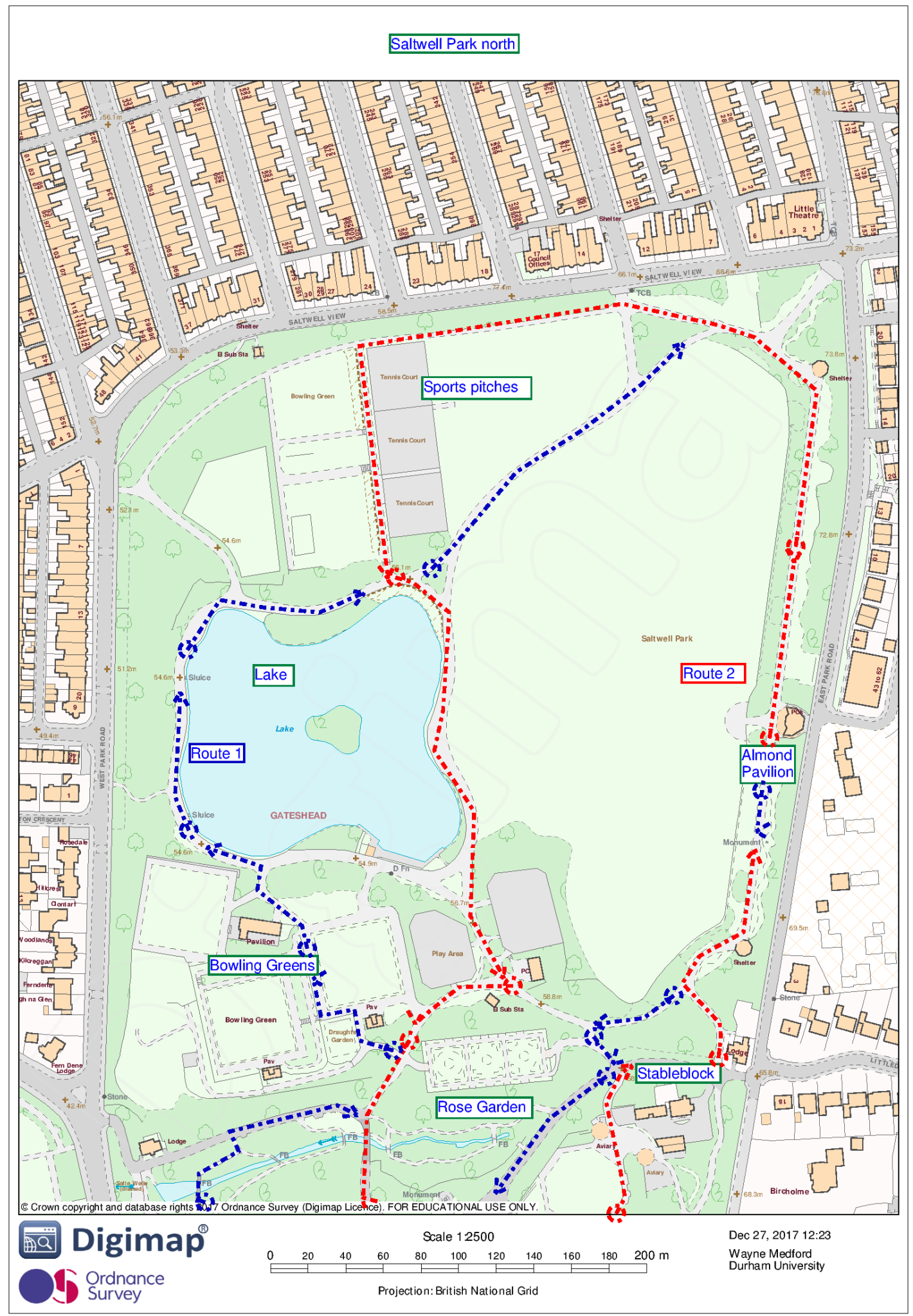

Figure 5. Walking routes through the northern half of Saltwell Park.

As observed by Lee and Ingold (2006), following a map does not necessarily equate to experiencing a place. The pilot work allowed me to understand how the subspaces interlinked, to gauge the distances from footpaths to the boundaries of the park, and to acquire a feel for what the ambience of the park was. The creation of the two routes emerged from strolling around the park, and efficient attempts at 
observation. Moreover, most other park users follow the footpath network, so I not only match the speed of most others, but also their directions and congregations too.

The two routes started from the car park, since driving to the park was the easiest means of travel. Getting from the car park involved going past the Crematorium, Bandstand and War Memorial (though these three spaces could be walked through to their west or east). The reader will notice that several spaces are common to each route; the other spaces would be observed on alternative visits. Those spaces common to each route tended to be the most populated, so being able to observe and record their lives seemed to be most important. Regarding the utilisation of the routes, I would walk one route per visit to the park; I would then employ the other route on the next visit, a variation on the algorithmic alternation.

I combed my surroundings from the footpaths, and would let my attention be caught by the interesting, unusual, and the sudden. For each visit, I would interrogate anything that I saw, heard or smelt that attracted my interest. Broadly speaking, I would ask: "What is it?" "What does it seem to do?" "What is its history?" "How do people interact with it?" "What effect does it seem to have upon those nearby people?" Thus, I would ask this of diverse features such as vegetation, wildlife, memorial plaques on park benches, leaflets, and posters around the park. I did not approach any visit with a pre-determined list of things to look for; instead, I tried to be open to the presence and operation of prominent features, as well as exploring areas and elements that were hidden, or unfrequented. For me, I was alert for something unusual, startling, or pleasurable; something which might act as a contrast to what appeared to be the usual pattern of occurrence.

In common with Bassett (2004), I did not stick rigidly to my routes. Even though my routes followed the existing footpath network within the park, I would frequently alter them subtly as the surroundings (or occasionally, my inclination) took me. As part of my visits around Saltwell Park, I would observe those individuals who were using the park for a given activity, such as running, or feeding animals, or meeting with people. Without being intrusive, I recorded their actions and behaviours. I could get close to people to overhear their discussions of their behaviours and experiences conversations unobtrusively; or capture settings, behaviours. On some days, I would deliberately improvise a route, by straying off Routes 1 and 2 for a little while, interrupting the pre-scripted route. For example, walking over grassy areas to sample the ambience, or to get close to observe previously distant park users, or to get a slightly different sensory perspective on the wider park. I sought to adopt the maxim of Smithson that my "walking conditioned sight, and sight conditioned walking, till it seemed only the feet could see" (Careri 2002).

Sontag (1978) commented that the "The photographer is an armed version of the solitary walker [... ]". Furthermore, I would walk through the park, noting what I saw on notebooks, digital camera, and digital audio recorder (Bassett 2004). These were available for review afterwards ${ }^{6}$.

As I have mentioned, any place characteristics can be subject to variation through time, due to weather, seasonality, social events, etc. When should one walk through a space? Will one journey be enough to capture its representative ambiance? What if an event, such as the activities of a given group which frequents the location, is missed? It can be thought that the life of an urban space could approximate to a patchwork quilt: at first glance, a single surface, but made up of many different pieces, each made of separate fabrics, which offer contrasting similarity and contrast in texture, origin, longevity, and prominence. To truly attend to a given place just once might risk prioritising one time-space texture, and missing others: darkness, the still, the empty, and the exceptional.

Classic ethnography has required a degree of immersion within a cultural space, in order to attend to details, patterns, and longevity (such as to observe power and governance: for example, Schatz 2013; Crewe 2014). Herbert (1998) comments that "considerable time" is required to grasp the "richness

6 Similarly, several artists have used walking to explore their immediate surroundings, as well as exploring personal histories; an example is Of Walking, http://www.mocp.org/pdf/exhibitions/of-walking/ow-designed-essay_compressed. pdf (accessed on 8 January 2018). 
and complexity" of a site, to produce nuanced analysis and description. Loïc (2004) famously spent some three years studying boxing in Chicago. Shah (2017) recommends fieldwork for at least one year. Debord's dérives would last from days to a week. Bassett's students could dérive for periods of their choice: an hour, or a day; they were asked to consider whether environmental ambiences changed with the diversity of life, and the passage of time. However, prolonged, intensive spells in a field-site maybe neither practicable, nor tolerable (Pink et al. 2010).

The study of cultural-spatial details and patterns can also be undertaken not just through participant observation, but also through observation. I would also suggest that there is a correlation to the amount of time to be devoted to data gathering (Galton et al. 1980; Galton 2006). However, the intensive capturing of the dynamic qualities of a place or a landscape and resultant outcomes is relatively rare. One example is Whyte (1988) whose research team spent six months using time-lapse photography to trace the diurnal patterns of social congregation and movement within a public square (each over the course of a day). To repeat this method requires accessible buildings which can afford high-level access, plus cameras which can cover the entirety of a space; without these opportunities, similar overview studies would present a significant challenge.

I am suggesting here that a place, especially one that is materially and symbolically complex (Delanda 2006) might require a degree of immersion; nonetheless, it is clear that it can be time-consuming. If the principle of immersion within a location is accepted, then other tactics could be sought. One possible compromise might be a sampling-based participant observation frame.

Some walking-based research studies have resorted to using several walks to gather data about a phenomenon, such as how individuals relate to each other within a given landscape (Darby 2000; Doughty 2013). Here, several (different and separate?) walks were undertaken. This approach could be utilised with a place itself: multiple walks, suitably scheduled to cover variation.

The nature of the time-spaces under consideration may require sampling-type ethnography methodologies; for example, multiple sites meant that Freidberg (2001a) could only spend limited amounts of her 15-month's total fieldwork time at each location, whilst Roy (2012) had to conduct her fieldwork over separate, protracted time-space frames. Regarding some examples of step-in-step-out, Morris (2015) scheduled fieldwork around an office's hours, Bhardwa (2013) around music events.

Ethnographic observation already utilises the concept of sampling (Hammersley and Atkinson 2007). Sampling has been used for recording specific activities and phenomena within office settings (e.g., Jenkins et al. 1975), and also, more relevant here, for recording phenomena during specific time periods; for example, during observational classroom-based research, Croll (2006) sampled using random time-slots.

A similar sampled practice of walking has been employed in the everyday; for example, the Cardiff homeless "outreach" team mentioned earlier (Smith and Hall 2016) undertook two daily patrols, each of at least two hours duration. Heddon and Turner (2012) discuss the London-based triumvirate, walkwalkwalk ${ }^{7}$ (Clare Qualmann, Gail Burton and Serena Korda), operating from 2005, with twice-annual walks supporting a mapping of the changes of London's East End. In addition, Jepson and Clarke (2016) reveal Jepson's observational schedule at a festival, which encompassed several weeks and time periods, across multiple sites.

My scheduled visits to Saltwell Park were normally one sequential day during the week, every week-for example, Monday week 1 , Tuesday week 2, Wednesday week 3, etc. Walks were conducted approximately once every week. Thus, I could compare any day of the week with others in subsequent weeks, or weekdays and weekends with others. It would normally take about $1 \mathrm{~h}$ to stroll around either route, regardless of interrupting a walk with some observations within the Towers, both upstairs and downstairs.

7 http://www.walkwalkwalk.org.uk/ (accessed on 8 January 2018). 
The earliest visit that I paid to the park was just after 07:00 on a still-dark February 3rd morning, 2009 (I saw a couple jogging, and no-one else). The latest was on Wednesday 24 June 2009, at about 22:00-22:30 (there was a private event on inside the Towers, with music carried on the air. I noticed a few other visitors within the park, as well as some young people on an adjacent road). I only attended these two extremes twice in total. Most visits were during more regularly inhabited hours, such as mid-morning, lunchtime, early afternoon, late afternoon and mid-evening. Fieldwork was carried out during January 2009-February 2010.

More broadly, my visits to the park were based upon a presumption that I would see the general, "routine" life of the park, typical of the "everyday" environment. Sometimes, an unusual event would occur, such as certain weather events. However, I had no prior knowledge of what I might see in the park, who I might find there, and what conclusions I may draw from those observations. I was effectively "sampling" the life of the park, through repeated observations of its form(s) over time, its constituent actants and their interconnections and actions upon others.

\section{Results: Walking through the Park}

A basic fabric of Saltwell Park: During the period of observations, the weather was mainly dry and conducive to visits. I was fortunate to experience little in the way of harsh weather on my myriad visits. Nonetheless, my first few walks were undertaken in deep snow. As it turned out, the winters of 2008-2009 and 2009-2010 were noteworthy in that regard. My very first trip was to a "winter wonderland", almost still, apart from brief flurries of falling snow, and grey skies. The only other visitors that day were a man walking slowly across the fields through the snow, accompanied by his Border Collie dog. Snow did not always necessarily keep visitors away, as I return to later.

I was able to discern some patterns in the design and management of Saltwell Park which had the potential to influence wider health-related behaviours. In the park's past (1970s and 1980s), disrepair, vandalism and anti-social behaviour, were endemic, in common with other urban parks. On many of my walks, I could observe at least uniformed park warden on patrol. I noted the twenty-or-so prominent, newly installed surveillance cameras, keeping a motionless watch.

Attempts were made to make the park specifically attractive to families. The provision of play areas, which looked well maintained, and which were often busy. In addition to that, one of the windows of the Towers' café carried a sticker which declared that breastfeeding was acceptable here, part of a public-private initiative (Gateshead MBC 2006). The breastfeeding friendly sticker was symbolic of an official welcome and permissiveness (Gateshead MBC 2006) which, at that time, was not legally enforced across England (NHS Choices 2015; NHS Choices 2017).

The park is used a hub for other public health campaigns. Within the Towers, especially downstairs, the café walls are used for exhibitions aimed at the public, but which are not advertised; for example, a public health campaign to mark World Mental Health Day, or artwork from schoolchildren warning against littering.

Dwelling for individuals: As I mentioned earlier, the weather during my fieldwork was generally conducive to prolonged immersion and observation. During warmer summer days, the hexagonal benches that were dotted about in some corners of the fields were populated by picnicking family and friendship groups. Some visitors brought deckchairs and foldable seats, together with windjammers, creating an impression of an inland beach. There was little rain. The most "extreme" weather was snow; park visitors had mixed responses to engaging with such weather. The man and his Border Collie were gaining the benefits of physical activity whilst trudging through ankle-deep drifts. For some family groups, the snows of 2009-2010 presented opportunities for pleasure. On one day during which local schools were shut (but the park was still open), many diverse groups brought in sledges to race down the steep grassy bank in the Grove (see Figure 6). 


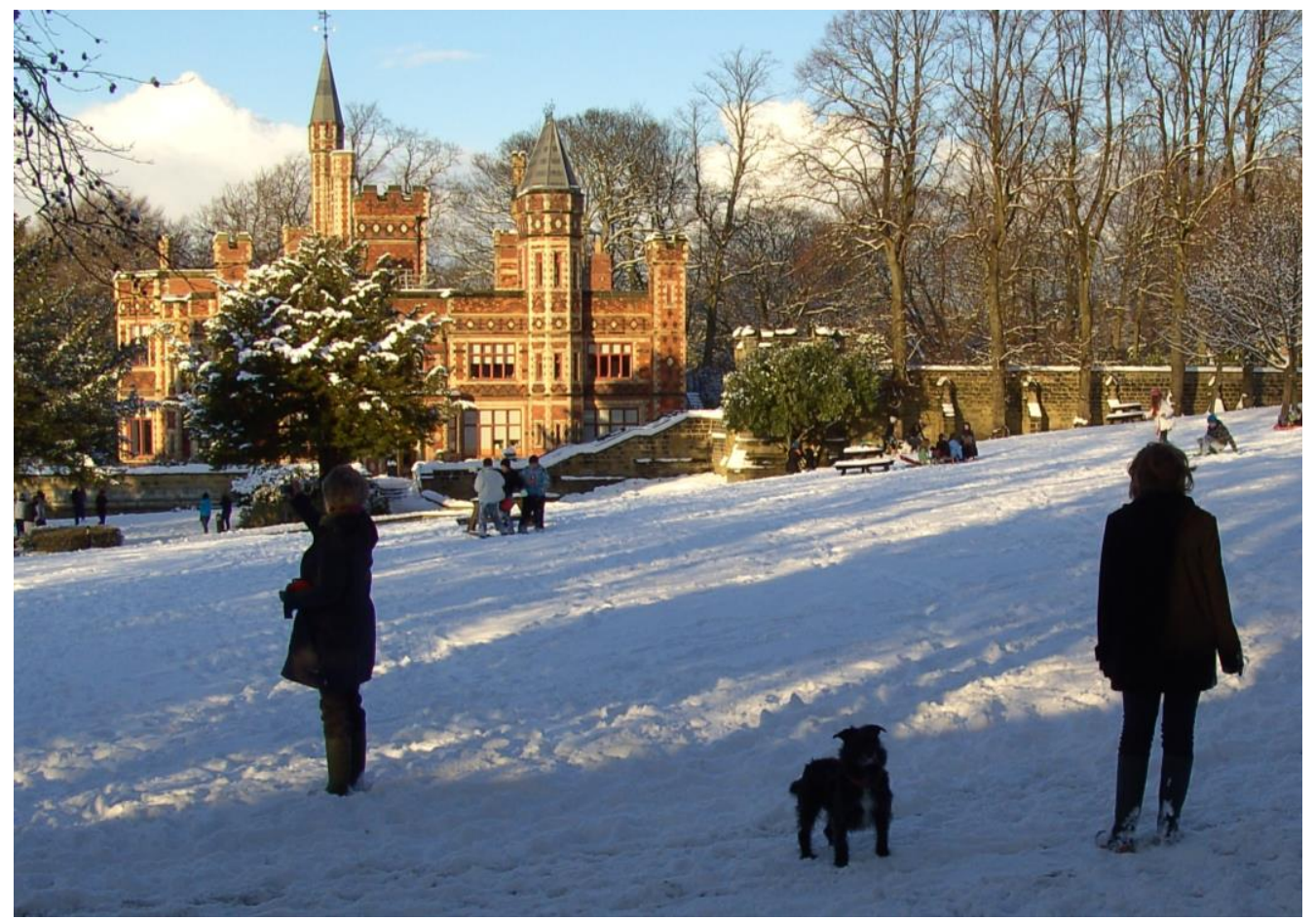

Figure 6. The Towers.

Saltwell Park often saw informal athletic activity. Apart from rise-and-shine joggers mentioned earlier, most others waited until daylight, usually lunchtimes or evenings. On one late-morning, soldiers (from the local barracks) suddenly appeared, to run towards the Dene. On another day, I inadvertently followed a man using the park furniture as if it was cross-training equipment (I prompted him to act self-consciously).

Parks were intended to bring human and nonhuman into close co-existence. There has been an animal presence in the park since 1881 (Gateshead MBC n.d.). Peacocks, rabbits, guinea pigs and exotic animals are kept in cages within the Aviaries. My walks revealed visitors of all ages as being fascinated and amused by them. In line with a suggestion of McCabe (n.d.), on one occasion (10 January 2009), I moved quietly and unobtrusively to within earshot of two women who I could hear talking by the Lake, whilst they were observing the birdlife. Once close, I listened to one woman discussing with another, possibly her mother, that she recognised some of the nearby ducklings, and how they had grown over several months. The example here illustrates that observations of animals, and other visits to the park, can be set against the passage of time, human lives, and that the lives of features therein similarly placed.

In the café, I occasionally observed mothers breastfeeding infants, with no signs of unwelcome interventions and microaggressions. Whilst later discussing the inaugural local Breastfeeding Awareness Picnic (held in the park in May 2009) with one attendee, we both acknowledged the Towers' café sticker as affording that permissiveness.

On Wednesday June 24, I happened to go to the park in both the morning and evening. An example of the hidden side to Saltwell Park can be seen in my morning observations of some signs of apparently secret behaviour, as denoted by some left-behind packaging secreted within the park. There was a gap that I had noted within a clump of central planting, which provoked my curiosity-it had not seemed to have been there before. Through the opening, in the clearing, I took some photographs, and recorded what I saw and felt. Even now, I cannot be entirely sure what it was that I had observed, beyond the obvious leaving behind of litter-was it activity which was largely medical (the innocent injection of insulin?), or something more-consuming alcohol and cigarettes? I investigated the location a few 
days later, and it had been cleared. I was lucky to have spotted the gap at all, within my peripheral vision. Seemingly, someone else had noticed it as well, and intervened.

The park affords dwelling to various community groups and individuals to appropriate spaces to mark their personal interactions and attachments. Within the first floor of the Towers, a glass cabinet holds the trophies that local Bowls' clubs have won over several decades. More widely, Saltwell Park serves as a significant communal space of remembrance for the town of Gateshead. There are memorials, plaques, and statues, to significant local figures. There is a mixture of civic tributes to both civilians and military service personnel. Many more informal, private, plaques have also been installed on most of the many benches located along the footpath network, some of which also record the names of armed service personnel, plus others who had not obviously been in uniform (see Figure 7). For example, one seating bench carried a dedication to one "Tommy Sergison", whose commission into the Durham Light Infantry during the Second World War, as well as his marriage to the late Viola, were remembered with a metal plaque. A bunch of flowers would often appear, tied to the side of the bench, to the arm-rest, at various times of the year, not only associated with major military anniversaries (such as the UK's Remembrance Day, November 11).

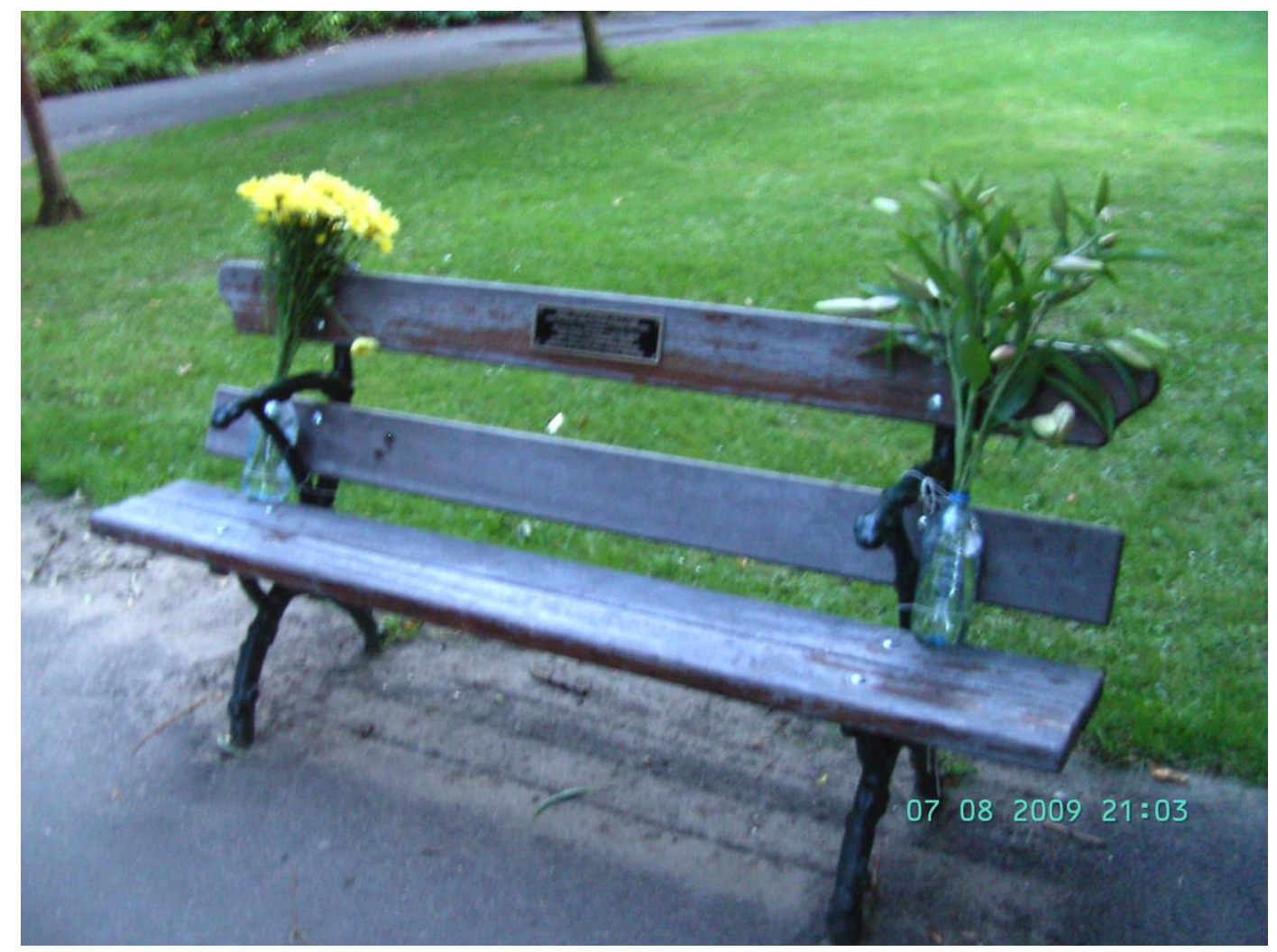

Figure 7. A memorial bench.

My own Dwellings: Overall, my walking was comfortable. Walking for an hour or so was not tiring. I realise that I rarely sat down on a bench as a stationary observation point; I tended to be mobile. It was in the café that I tended to sit, since it is a space dominated by chairs and tables.

I did have a semi-official role within the park, having joined the Friends' group, initially to facilitate my overall fieldwork. Thanks to my friendly engagements with its members, I grew to feel a sense of attachment and responsibly towards the park. I approached one of the wardens, when, during the autumn of 2009, some park users, including some adults with young children, threw sticks up at the branches of some horse chestnuts, trying to knock conkers down. 
Overall, visitor groups did not obviously interact with each other. Several dog walkers would greet me on the footpaths with a smile and a "hello". My research was approved by Durham University Geography Department: as part of my ethical approval documentation, I mused aloud that my research would expose me to racist microaggressions. In effect, I was testing a minor hypothesis through my fieldwork. As a black researcher, my interactions, in this largely white populated park, were generally pleasant and unremarkable.

On one occasion (March 22), I found that I was being tracked by a CCTV security camera near the Bowling Greens, one of the several to be installed in the park with restoration. I tested whether this was a deliberate tracking by resorting to an impromptu side-step dance. The camera followed me. It struck me that that the cameras did not always seem to track movement within the park; I watched their movements when I was in the park both before and after, and they rarely moved. This was the only occasion when I observed anyone within the park being tracked. Was this something for me to be concerned about? After all, the experiences of ethnic minorities in public parks have been often seen as problematic (Abercrombie et al. 2008; Gobster 2002; Byrne 2011; Byrne and Wolch 2009). Speaking to one of the wardens had previously informed me that the cameras were controlled off-site.

A transect through of year would reveal some of the range of potential physical and social dwellings for park users and staff to inhabit. The physical, designed, fabric changed relatively little throughout the year. Ingold (2010a) comments that weather plays a part in motivating human activity. The year opened with both thick snow on the ground, and grey, snowy skies above and around. Otherwise, the year's weather was generally pleasant (for example, in Figure 8); sometimes sunny, sometimes, overcast. As a result, the park tended to have enjoy a constant throughflow of visitors.

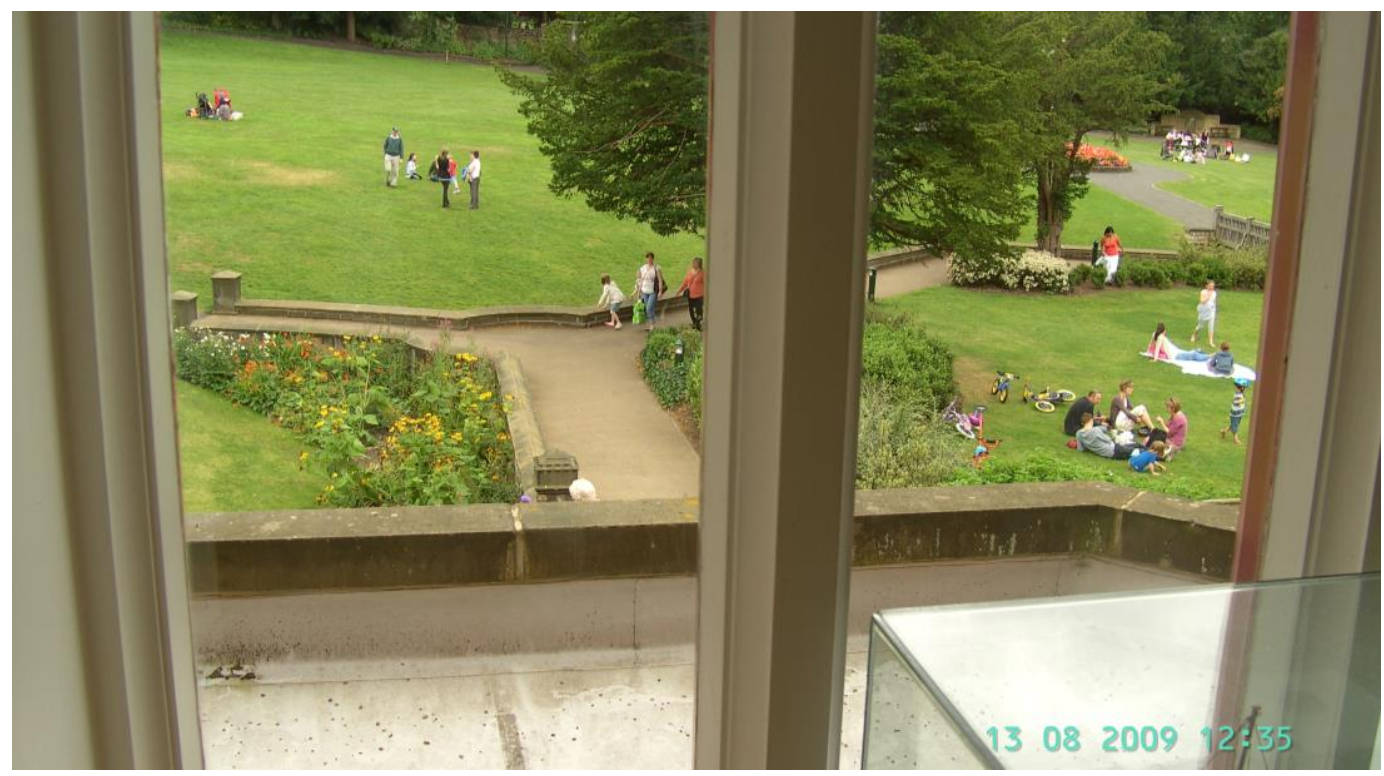

Figure 8. Looking south from the Towers.

Visitors could get close to animals around the Lake and at the Aviaries. Wild birds at the Lake would swirl and throng at the merest hint of visitors proffering food. The aviary animals—birds and mammals-could take-or-leave human attention. Elsewhere, wildlife encounters were occasional and unpredictable-a blackbird darting within the undergrowth, a grey squirrel spiralling around a tree trunk, a whiff of scent, for example.

The organisation of the park seemed to be aimed at encouraging and reassuring a (largely family-based) clientele. It was noticeable that weekday family groups tended to be focussed around mothers and grandparents. They were likely to have seen at least one warden on their trips. The park was always tidy, and well-groomed, which made the discovery of the hidden, illicit, retreat all the 
more surprising. It was the only occasion when it seemed (to me) that the park had been used in this way. One interview participant observed that for the new mothers that she knew, a well-maintained appearance and the presence of security was reassuring. For her, these facets implied that there would not be the presence of potentially threatening others within the park, who might wish to vandalise parts of the fabric, leaving it unsafe or unattractive, or who might be suddenly encountered whilst walking in quiet parts of the park. The design of the park, especially with regard to high, thick, vegetation, and a lot of corners, did offer some potential hiding spots. I had to concur with the participant above; my observations were conducted without my feeling that I had to be aware of my own safety as a lone individual.

There tended to be differences in which groups and demographics inhabited the park during various times of a typical day. Only the park wardens and the very keen runners were around the time of park opening. Children, often in their early teens, would pass through the park to go to school between the hours of 8 and 9 a.m. The mornings would see family groups emerge and loiter within the park; their main spaces were the play areas, Lake and aviaries for engaging with animals, the cafe for refreshments, with the footpaths for slow walks. Some model boaters would emerge during the day, with some more bringing their craft during down late afternoons. The schoolchildren would re-emerge mid-afternoon, between 3 p.m. and 4 p.m., once school had finished for the day; it was outside these school hours that some of these older children would be a more noticeable presence within the park. Even during long summer holidays, I did not register a significantly greater presence of older children within their mid- and late-teens. Saltwell Park would become progressively quieter during the early evenings; casual visitation would start to fade.

Some working-age adults would however start to emerge, participating in exercise classes which were organised by a fitness company on Thursday evenings during the summer months. For most visitors it was a leisure space, one to enter as part of a casual routine. Even though almost everyone walked (and in theory, gained some physical activity), only a few utilised the park for more energetic, regimented activities.

There are many benches sited along the various footpaths, almost all with commemorative plaques on. Friends and relatives would lay floral tributes on ones relevant to them, throughout the year. These times were not particular to any wider commemorative dates or festivals, sometimes not linked to any obvious dates listed on the plaques themselves.

The year ended with some more snow, but in the context of sunnier days instead of the grey skies of 12 months before. The park was quiet; the events had largely finished. After Bonfire Night (November 5) came Enchanted Park (early December), one of few night-time events across the year. Compared to winter days, it brings crowds into the park, offering its own (sensory) winter wonderland.

\section{Discussion}

My routes were akin to the algorithmic dérives of Social Fiction ${ }^{8}$ (Bassett 2004). I could have introduced a playful element of a coin-toss to decide which route to choose, per visit.

I did not have to start with one destination. There are ten entrances to the park; all of which I passed through on other occasions during that year. Perhaps, I could have devised other routes which allowed me to observe the main park spaces too, using these other entrances.

My methodology more concerned with recording people, animals, objects, and activities. One facet of the dérive which I borrowed for my walks was to let my attention drift, whilst following my routed walks. If a dérive could be thought of an unstructured interrogation-cum- "interview" of the material and sensory characteristics, and affects, of space and place, then my walks were semi-structured, with

8 See also https://en.wikiversity.org/wiki/Psychogeography/Algorithmic_Psychogeography; http://www.utne.com/ community/a-new-way-of-walking (accessed on 8 January 2018). Being completely random in route choice, or being able to shed expectations, in so relatively small, increasingly well-known, and indeed, well-ordered space, might have been more difficult. 
my curiosity taking me occasionally off piste. My memory would subconsciously compare the vegetated copse in the middle of the park, and for one moment, determined that something was missing-a hole had appeared in the shrubs that had not apparently been there before during my previous visits, which seemed to penetrate deep into the vegetation, and that might be worth investigating. The senses operated on several levels (Overall 2017): the conscious, directed towards combing for new sights, sounds, smells—what might those people gesticulating at? —with the peripheral also running, trying to determine whether something might be happening just out of sight, behind a wall, at the brow of a slope, just out of earshot. My memory was also running in the background. Was that gap there before? Have I ever seen a security camera move before? My engagement with the hidden den was a Debordian alertness for spaces and activities behind the manicured façade of the park.

More widely, Boyd (2009) observes that urban parks offer a sensory and embodied separation from the (archetypal, stereotypical) hustle and bustle of other parts of the urban fabric. Their design logic draws in natural textures which foreground vegetation, wildlife and open skies, over concrete, tarmac, glass and steel. The senses would be differently engaged; listening could be more concerned with being attuned to detecting faint, occasional, singular, sounds, than decoding a multitude of simultaneous ones. Plants scents could be occasionally detected, such as mahonia japonica, not necessarily a typical street scent. The sound of passing trains from the railway felt like occasional intrusions. The temporary exclusion of "typical" urban life experiences is one of the attractions of urban parks; the pace of life is pedestrian, transport modes are fleshy, background sounds often much quieter.

With respect to in-person data gathering, normal (participation) observation methods can apply. I found that using digital audio technologies was useful for unobtrusively recording my own vocal narrations and ambient recording, especially if it could be hidden among clothing. Nonetheless, I was sensitive to ethical considerations of recording other people's actions and interactions in situations that were private, or where privacy has been anticipated.

Repeated walking trips allowed me to make comparisons of each part of the park at that moment to previous times. I did not seek to take photographs from the same location: I took them of anything which interested me at that given moment. Nonetheless, I gained an overall impression of how particular spaces were populated and inhabited, and the cycles and rhythms which attended these.

My observational work was a form of "step-in-step-out". Some observational sampling methodologies by, for example, Croll (2006), Galton (2006), Galton et al. (1980), have used regular timetabling of observations. The temporal schedule of my visits could have been further systematised, if I had wished, or had been able. It is possible to, for instance, make a first park fieldwork visit on Monday at opening time (e.g., 8 a.m. for an hour), the next on Tuesday at 9 a.m.-10 a.m., Wednesday 10-11, etc., until a visit coincides with closing time. Then the next cycle could repeat.

The idea behind the sampling frame is that anything interesting (and indeed, unusual) could randomly occur at any part of the park, and at any time. Thus, a timetabled slot for a walking sortie to occur is relatively likely to coincide with it. Ingold (2016b) asserts how life is lived in lines; the line of travel of my walks was intended to coincide with an event which might have occurred and left a trace, or indeed was going on at the same time as I passed by. Thus, my walk would coincide in time-space with an event, or some phenomenon. However, something noteworthy could occur in the park at the other end of my walking route just as I set off, finished it, or occurred behind me just as I passed around a corner. Only in a space which is so small that a stationary researcher could take in its extent in one sensory sweep (line-of-sight, earshot, etc.) could every detail be gleaned by an observer; otherwise, unless one has a team of observers and informers (or cameras, like Whyte), some event(s) will inevitably be missed. The overall aim will be to obtain an impression of how large, materially and socially complex locations operate at the given moment in which a walker passes through. I would impress upon the reader that these time periods did not necessarily determine the amount of time that I would spend in the park for all visits. For example, I was a participant observer during some other visits, generally during events. These had durations of up to an hour, sometimes longer (the longest that I spent attending an event was over five hours). 
Overall, these walking tours gave me important foundations and insights for other aspects of my wider fieldwork. I was able to observe Saltwell Park's formal, designed, spaces and its impromptu, ephemeral, ones. Some of these were not on the "official" visitor map. For the sake of simplicity, I have not discussed those scheduled events which I attended as an observer, but accessing these required walking through the park, and through the event. I could combine event attendance with "park surveillance". I could compare my observations and experiences to those park users who I interviewed during the same period. They would describe and discuss their space-time landscapes within the park, of which I had some additional insight through my tours. Walking was also part of a wider embodied immersion within the park, including participation observation.

Finally, walking allowed me to observe, experience and contemplate the nature of possible dwellings within the park. Some forms of materiality and possibilities for inhabitation remained constant throughout fieldwork period; generally, these pertained to attempts to make the park seem welcoming and inclusive. An example of this was the park's breastfeeding status; its spatiality was park-wide, though this status was only signalled at the café. An affective sense of security came from the presence of fixed cameras and regular, and unscheduled observations of at least one warden; like me, wardens were mobile and patrolled the footpaths. Some other dwelling forms were also long-lasting, such as the opportunity to leave tributes for loved ones on benches. Weather was more unpredictable; clearly, the seasons occupied months, but provided an umbrella for individual patterns of sunshine, wind, cloud formations, and occasional rain, to sweep in and linger overhead. My own encounters with other park dwellers were similarly unpredictable, centred around whoever might appear and come close, but enough followed a similar pattern of either disinterest or occasional interest and friendliness; maybe the CCTV camera operator was trying to be friendly too ... no police arrived looking for me ... Moreover, I was among the flows of materialities, spatialities and temporalities, which suggested environments, and forms of inhabitation which could support individual or group access and dwelling within. I was both able to compare my observations to those of participants, and add additional perspective. Certain wellness opportunities for sociability or retreat, for physical activity, closeness with forms of the natural, encouraged within the public realm, could thus emerge.

\section{Conclusions}

Ochoa (2009), I attempted to systematically experience and understand the materialities, spatialities, and temporalities, of a portion of a potentially therapeutic urban landscape through walking. Public parks are not a landscape always at the forefront of discussions of ethnographies of city life, which typically tend towards urban centres and residential areas. By attempting a systematic walking methodology, I wanted to give myself a pattern of visits which could give me a baseline of empirical data to know, analyse and represent Saltwell Park; not just as transect across its physical extent, but also through time. It is beyond the scope of this paper to discuss wider analyses of my data, and the compilation of a representation of the life of the park.

Debord (1958) felt that collective walking was the best way to undertake a dérive. My walks could otherwise have been undertaken as a group exercise, which would have increased the eyes, ears, and hands available to sense and record. Shared experiences of modes of mobilities have taken place elsewhere (Bissell and Overend 2015; Doughty 2013). Walking also has a gendered historiography (Heddon et al. 2009; Heddon and Turner 2010); Bassett (2004) raises the issue of whether his students felt differently about spaces according to their gender (though other experiences of urban space, dispositions and embodiment can also be relevant (see for example (Koskela 1997; Koskela and Pain 2000).

One effect of my attempts to constantly scan my surroundings and record what I saw, was that I attempted to uncover and record nuance of Saltwell Park's life behind its official (and popular) imagery as a popular, homely, award-winning park. In saying this, I am very fond of Saltwell Park, and I am not trying to suggest that it serves as a capitalist façade in the Situationist lexicon, which obscures an authentic life, and which needs to be exposed and usurped. It is a park which has CCTV cameras and 
a uniformed warden presence. I twice observed police vehicles suddenly appear and drive around the Lake and Long Walk. Saltwell Park may not necessarily be of the Gateshead conurbation, but it is still part, and will share the issues which the wider town will have. Saltwell Park was home to a hidden spot which appeared to be a place to illicitly consume substances. I tried to be curious and credulous of all that I encountered, and, when no-one was looking, to slip into mysterious openings and see what I might see.

One time in which I performed a form of Debordian "transgression" (Bridger 2014), was through my performance with the CCTV camera. I reversed the polarities of CCTV engagement, whereby the watched acknowledges, meets, and challenges the gaze of the watcher (Graham et al. 1996; Foucault [1975] 1977). One implicit dimension of the CCTV presence is that the watched should keep calm, carry on regardless, and let themselves be watched by the watchers.

To summarise, the principles guiding my methodology is that walking is shaped by the landscape it is to be performed in, the rationale for the walk, and the walker's conduct. Of interest to me here is immersion within a given space over a lengthy duration, to gauge materialities, spatialities and temporalities, to sample the regular, and (hopefully) intercept the unusual. I suggest in this paper that a walking methodology can be combined with tools from other qualitative methods, to achieve a possible methodology which allow for a temporally and spatially sample-based pedestrian ethnographic immersion in a select site, based not just around the linear performance of a single walk, but also through their cyclical, repetition.

Acknowledgments: Thank you to Les Roberts and the Humanities editorial staff for their help, and to my anonymous reviewers for their comments. A Thank You also to Jennifer Lawshaw and Rachel Colls for their suggestions and encouragement. The biggest Thank You to Sylvia and George Medford.

Conflicts of Interest: The author declares no conflict of interest.

\section{References}

Abercrombie, Lauren C., James F. Sallis, Terry L. Conway, Lawrence D. Frank, Brian E. Saelens, and James E. Chapman. 2008. Income and racial disparities in access to public parks and private recreation facilities. American Journal of Preventive Medicine 34: 9-15. [CrossRef] [PubMed]

Anderson, Elijah. 2000. Code of the Street: Decency, Violence, and the Moral Life of the Inner City. New York: WW Norton \& Company.

Bassett, Keith. 2004. Walking as an aesthetic practice and a critical tool: Some psychogeographic experiments. Journal of Geography in Higher Education 28: 397-410. [CrossRef]

Bendiner-Viani, Gabrielle. 2016. Walking, Emotion, and Dwelling. Space and Culture 8: 459-71. [CrossRef]

Bennett, Jane. 2005. The agency of assemblages and the North American blackout. Public Culture 17: 445-65. [CrossRef]

Bhardwa, Bina. 2013. Alone, asian and female: The unspoken challenges of conducting fieldwork in dance settings. Dancecult: Journal of Electronic Dance Music Culture 5: 39-60. [CrossRef]

Billo, Emily, and Alison Mountz. 2016. For institutional ethnography: Geographical approaches to institutions and the everyday. Progress in Human Geography 40: 199-220. [CrossRef]

Bissell, Laura, and David Overend. 2015. Regular Routes: Deep Mapping a Performative Counterpractice for the Daily Commute 1. Humanities 4: 476-99. [CrossRef]

Boyd, William. 2009. It's All Too Beautiful. The Guardian. Available online: http://www.guardian.co.uk/books/ 2009/jun/20/william-boyd-park-stories (accessed on 5 February 2010).

Bridger, Alexander John. 2014. Visualising Manchester: Exploring New Ways to Study Urban Environments with Reference to Situationist Theory, the Dérive, and Qualitative Research. Qualitative Research in Psychology 11: 78-97. [CrossRef]

Byrne, Jason. 2011. When green is White: The cultural politics of race, nature and social exclusion in a Los Angeles urban national park. Geoforum 43: 595-611. [CrossRef]

Byrne, Jason, and Jennifer Wolch. 2009. Nature, race, and parks: Past research and future directions for geographic research. Progress in Human Geography 33: 743-65. [CrossRef]

Careri, Francesco. 2002. Walkscapes: Walking as an Aesthetic Practice. Barcelona: Gustavo Gili. 
Castells, Manuel. 1972. Urban renewal and social conflict in Paris. Social Science Information 11: 93-124. [CrossRef] Cattell, Vicky, Nick Dines, Wil Gesler, and Sarah Curtis. 2008. Mingling, observing, and lingering: Everyday public spaces and their implications for well-being and social relations. Health E Place 14: 544-61.

Conradson, David. 2005. Landscape, care and the relational self: Therapeutic encounters in rural England. Health Place 11: 337-48. [CrossRef] [PubMed]

Conway, Hazel. 2000. Parks and People: The social Functions. In The Regeneration Of Public Parks. London: J Woudstra. E \& FN Spon.

Cook, I. 2005. Particiapant Observation. In Methods in Human Geography: A Guide for Students Doing a Research Project. Edited by R. Flowerdew and D. Martin. Harlow: Pearson.

Crewe, Emma. 2014. Ethnographic research in gendered organizations: The case of the Westminster parliament. Politics \& Gender 10: 673-78.

Croll, Paul. 2006. Teacher interaction with individual male and female pupils in junior-age classrooms. Educational Research 27: 220-23. [CrossRef]

Dalsgaard, Steffen, and Morten Nielsen. 2013. Time and the Field. Social Analysis 57: 1-19. [CrossRef]

Darby, Wendy Joy. 2000. Landscape And Identity: Geographies of Nation \& Class In England. Oxford: Berg.

Debord, Guy. 1958. Theory of the Dérive. Bureau of Public Secrets. Available online: http:/ /www.bopsecrets.org/ SI/2.derive.htm (accessed on 8 January 2018).

Delanda, Manuel. 2006. A New Philosophy of Society: Assemblage Theory And Social Complexity. London and New York: Continuum International Publishing Group.

Doughty, Karolina. 2013. Walking together: The embodied and mobile production of a therapeutic landscape. Health Place 24: 140-46. [CrossRef] [PubMed]

Edensor, Tim. 2010. Walking in rhythms: Place, regulation, style and the flow of experience. Visual Studies 25: 69-79. [CrossRef]

Forrest, Ray, and Ade Kearns. 2000. Social Cohesion, Social Capital and the Neighbourhood. Paper presented at the ESRC Cities Programme Neighbourhoods Colloquium, Liverpool, NY, USA, June 5-6.

Foucault, M. 1977. Discipline and Punish: The Birth of the Prison. London: Penguin. First published 1975.

Freidberg, Susanne. 2001a. Culture, Conventions and Colonial Constructs of Rurality: Histories and Geographies of Difference in the Afro-European Fresh Produce Trade. Dartmouth: Dartmouth College.

Freidberg, Susanne. 2001b. On the trail of the global green bean: Methodological considerations in multi-site ethnography. Global Networks 1: 353-68. [CrossRef]

Galton, M. Simon, Brian Simon, and P. Croll. 1980. Inside the Primary Classroom. London: Routledge and Kegan Paul.

Galton, Maurice. 2006. Systematic Classroom Observation: British Research. Educational Research 21: 109-15. [CrossRef]

Gateshead MBC. 2005. A Neighbourhood Plan for the Orthodox Jewish Community of Gateshead. Gateshead: Gateshead Metropolitan Borough Council.

Gateshead MBC. 2006. Breast is Best for Gateshead Business. Gateshead Council. Available online: http:/ / www.gateshead.gov.uk/Council\%20and\%20Democracy/news/News\%20Articles/Breast \%20is\% 20Best\%20for\%20Gateshead\%20Business.aspx (accessed on 20 August 2017).

Gateshead MBC. 2010. Be Enchanted at Saltwell Park. Gateshead_MBC. Available online: http:/ /www.gateshead. gov.uk/Leisure\%20and\%20Culture/parks/Saltwell\%20Park/Home.aspx (accessed on 1 February 2010).

Gateshead MBC. n.d. Saltwell Park Heritage Lottery Fund Urban Parks Programme. Gateshead: Gateshead MBC.

Gesler, Wilbert M. 2003. Healing Places. Lanham: Rowman \& Littlefield.

Gesler, Wilbert M. 2005. Therapeutic landscapes: An evolving theme. Health Place 11: 295-97. [CrossRef] [PubMed]

Gobster, Paul H. 2002. Managing urban parks for a racially and ethnically diverse clientele. Leisure Sciences 24 : 143-59. [CrossRef]

Goltsman, Susan, Laurel Kelly, Susan McKay, Patricia Algara, and Larry Wight. 2009. Raising "Free Range Kids": Creating Neighborhood Parks That Promote Environmental Stewardship. Journal of Green Building 4: 90-106. [CrossRef]

Graham, Stephen, John Brooks, and Dan Heery. 1996. Towns on the television: Closed circuit TV in British towns and cities. Local Government Studies 22: 1-27. [CrossRef]

Hammersley, Martyn, and Paul Atkinson. 2007. Ethnography: Principles in Practice. London and New York: Routledge.

Harrington, Brooke. 2015. Immersion Ethnography of Elites. Handbook of Qualitative Organizational Research, $134-42$. 
Heddon, Deirdre, Carl Lavery, and Phil Smith. 2009. Walking, Writing and Performance: Autobiographical Texts. Bristol and Wilmington: Intellect Books.

Heddon, Deirdre, and Cathy Turner. 2010. Walking women: Interviews with artists on the move. Performance Research 15: 14-22. [CrossRef]

Heddon, Deirdre, and Cathy Turner. 2012. Walking women: Shifting the tales and scales of mobility. Contemporary Theatre Review 22: 224-36. [CrossRef]

Herbert, Steve. 1998. Policing contested space: On patrol at Smiley and Hauser. In Images in the Street: Planning, Identify and Control in Public Space. Edited by Nicholas Fyfe. London: Routledge.

Hillier, Bill. 1996. Cities as movement economies. Urban Design International 1: 41-60. [CrossRef]

Ingold, Tim. 2000. The Perception of the Environment: Essays on Livelihood, Dwelling and Skill. London and New York: Routledge.

Ingold, Tim. 2010a. Footprints through the weather-world: Walking, breathing, knowing. Journal of the Royal Anthropological Institute 16: S121-39. [CrossRef]

Ingold, Tim. 2010b. The temporality of the landscape. Contemporary Archaeology in Theory: The New Pragmatism, 59. [CrossRef]

Ingold, Tim. 2016a. Culture on the Ground. Journal of Material Culture 9: 315-40. [CrossRef]

Ingold, Tim. 2016b. Lines: A Brief History. London and New York: Routledge.

Jacobs, Jane. 2016. The Death and Life of Great American Cities. New York: Vintage.

Jeffrey, Bob, and Geoff Troman. 2004. Time for ethnography. British Educational Research Journal 30: 535-48. [CrossRef]

Jenkins, G. Douglas, David A. Nadler, Edward E. Lawler, and Cortlandt Cammann. 1975. Standardized observations: An approach to measuring the nature of jobs. Journal of Applied Psychology 60: 171. [CrossRef]

Jepson, Allan, and Alan Clarke. 2016. Creating Critical Festival Discourse through flexible mixed Methodological research design. In Critical Event Studies. New York: Springer, pp. 59-83.

Koskela, Hille, and Rachel Pain. 2000. Revisiting fear and place: Women's fear of attack and the built environment. Geoforum 31: 269-80. [CrossRef]

Koskela, Hille. 1997. 'Bold Walk and Breakings': Women's spatial confidence versus fear of violence. Gender, Place and Culture: A Journal of Feminist Geography 4: 301-20. [CrossRef]

Kusenbach, Margarethe Brigitte. 2003. Neighboring: An Ethnographic Study of Community in Urban Hollywood. Los Angeles: University of California.

Latham, Alan, and Derek P. McCormack. 2007. Developing 'real-world' methods in urban geography fieldwork. Planet 18: 25-27. [CrossRef]

Lee, Jo, and Tim Ingold. 2006. Fieldwork on foot: Perceiving, routing, socializing. Locating the Field: Space, Place and Context in Anthropology 42: 67.

Lefebvre, Henri. 2004. Rhythmanalysis: Space, Time and Everyday Life. London and New York: A\&C Black.

Loïc, J. D. Wacquant. 2004. Body and Soul: Notebooks of an Apprentice Boxer. Oxford: Oxford Universtity Press.

Lynch, Kevin. 1984. Good City Form. Cambridge: MIT Press.

MacFarlane, Robert. 2005. A road of one's own. Times Literary Supplement 7: 3.

Madden, Raymond. 2017. Being Ethnographic: A Guide to the Theory and Practice of Ethnography, 2nd ed. Thousand Oaks: SAGE Publications.

Massey, Doreen. 1994. Space, Place and Gender. Minneapolis: University of Minnesota Press.

Massey, Doreen. 2005. For Space. London, Thousand Oaks and New Delhi: Sage.

Massey, Doreen. 1991. A global sense of place. Marxism Today (June). MASSEY, D Flexible Sexism, Environment and Planning D: Society and Space 9: 31-58.

Matos Wunderlich, Filipa. 2008. Walking and Rhythmicity: Sensing Urban Space. Journal of Urban Design 13: 125-39. [CrossRef]

McCabe, Chris. n.d. Walking The City. Available online: https://poetryschool.com/assets/uploads/2016/01/ Chris-McCabe-Writing-the-City.pdf (accessed on 22 August 2017).

Merriman, Peter. 2004. Driving places: Marc Augé, non-places, and the geographies of England's M1 motorway. Theory, Culture \& Society 21: 145-67.

Morris, Nina J. 2011. Night walking: Darkness and sensory perception in a night-time landscape installation. Cultural Geographies 18: 315-42. [CrossRef] 
Morris, Rachel. 2015. 'Youth justice practice is just messy'youth offending team practitioners: Culture and identity. British Journal of Community Justice 13: 47.

NHS Choices. 2015. Breastfeeding in Public. Available online: http://www.nhs.uk/conditions/pregnancy-andbaby/pages/breastfeeding-in-public.aspx\#close (accessed on 18 August 2017).

NHS Choices. 2017. Breastfeeding in Public. NHS Choices, Last Modified 28/02/2017. Available online: http:/ / www.nhs.uk/Conditions/pregnancy-and-baby/Pages/breastfeeding-in-public.aspx (accessed on 14 February 2017).

Ochoa, Rita. 2009. The Importance of the Walk in the Analysis of Public Space. na. 3. Lisbon: Understanding the Post-Industrial City: Metropolis, Urban Renewal, Public Space Joint PhD Seminar.

Olmsted, Frederick Law. 1973. Forty Years of Landscape Architecture: Central Park. Cambridge: MIT Press.

Olmsted, Frederick Law. 1997. Public Parks and the Enlargement of Towns. In Civilizing American Cities: Writings on City Landscapes. Edited by Frederick Law Olmsted and S. B. Sutton. New York: Da Capo Press, p. 94.

Overall, S. 2017. Workshop and soundshot-A derive and participatory performance. PARtake: The Journal of Performance as Research 1: 42-46.

Peters, Karin, Birgit Elands, and Arjen Buijs. 2010. Social interactions in urban parks: Stimulating social cohesion? Urban Forestry \& Urban Greening 9: 93-100.

Pink, Sarah. 2008. An urban tour: The sensory sociality of ethnographic place-making. Ethnography 9: 175-96. [CrossRef]

Pink, Sarah, Phil Hubbard, Maggie O'neill, and Alan Radley. 2010. Walking across disciplines: From ethnography to arts practice. Visual Studies 25: 1-7. [CrossRef]

Roy, Ananya. 2012. Ethnographic circulations: Space-time relations in the worlds of poverty management. Environment and Planning A 44: 31-41. [CrossRef]

Schatz, Edward. 2013. Political Ethnography: What Immersion Contributes to the Study of Power. Chicago: University of Chicago Press.

Shah, Alpa. 2017. Ethnography? Participant observation, a potentially revolutionary praxis. HAU: Journal of Ethnographic Theory 7: 45-59. [CrossRef]

Sinclair, Iain. 1997. Lights Out for the Territory: Nine Excursions in the Secret History of London. London: Granta.

Smets, Michael, Gary Burke, Paula Jarzabkowski, and Paul Spee. 2014. Charting new territory for organizational ethnography: Insights from a team-based video ethnography. Journal of Organizational Ethnography 3: 10-26. [CrossRef]

Smith, Robin James, and Tom Hall. 2016. Pedestrian circulations: Urban ethnography, the mobilities paradigm and outreach work. Mobilities 11: 498-508. [CrossRef]

Sontag, Susan. 1978. Susan Sontag on Photography. London: Penguin Group.

Sotelo, Luis Carlos. 2010. Looking backwards to walk forward: Walking, collective memory and the site of the intercultural in site-specific performance. Performance Research 15: 59-69. [CrossRef]

Taylor, Dorceta E. 1999. Central park as a model for social control: Urban parks, social class and leisure behavior in nineteenth-century America. Journal of Leisure Research 31: 420-77. [CrossRef]

Thomson, Melanie S. 2007. Placing the Wild in the City: “Thinking with" Melbourne's Bats. Society and Animals 15: 79-95. [CrossRef]

Wheater, C. W., E. Potts, E. M. Shaw, C. Perkins, H. Smith, H. Casstles, P.A. Cook, and M.A. Bellis. 2007. Returning Urban Parks to Their Public Health Roots. London: Department of Environmental and Geographical Sciences Manchester, Metropolitan University; Liverpool: Centre for Public Health Liverpool, John Moores University.

Whyte, William. 1988. The Design of Spaces. In The City Reader. Edited by Richard T. LeGates and Stout Frederic. Abingdon: Routledge.

Williams, Allison, ed. 2007. Therapeutic Landscapes. Farnham: Ashgate Publishing Limited.

Cheng, Yi'En. 2014. Telling stories of the city: Walking ethnography, affective materialities, and mobile encounters. Space and Culture 17: 211-23.

(C) 2018 by the author. Licensee MDPI, Basel, Switzerland. This article is an open access article distributed under the terms and conditions of the Creative Commons Attribution (CC BY) license (http:/ / creativecommons.org/licenses/by/4.0/). 